
8 Research Square
Preprints are preliminary reports that have not undergone peer review.
They should not be considered conclusive, used to inform clinical practice,
or referenced by the media as validated information.

\title{
Machine Learning based Recommender Systems for Crop Selection: A Systematic Literature Review
}

\author{
Younes OMMANE ( $\nabla$ younes.ommane@um6p.ma ) \\ Université Mohammed VI Polytechnique \\ Mohamed Amine RHANBOURI \\ Université Mohammed VI Polytechnique \\ Hicham CHOUIKH \\ Université Mohammed VI Polytechnique \\ Mourad JBENE \\ Université Mohammed VI Polytechnique \\ Ikram CHAIRI \\ Université Mohammed VI Polytechnique \\ Mohamed LACHGAR \\ Chouaib Doukkali University \\ Saad BENJELLOUN \\ Université Mohammed VI Polytechnique
}

Research Article

Keywords: Recommender Systems, Collaborative Filtering, Crop recommendation, Crop selection, Machine Learning, Agricultural management practices

Posted Date: September 7th, 2022

DOI: https://doi.org/10.21203/rs.3.rs-1224662/v2

License: (c) (i) This work is licensed under a Creative Commons Attribution 4.0 International License. Read Full License 


\section{Abstract}

This paper draws a systematic literature review about the use of Machine learning based recommender systems for crop selection, with respect to the PRISMA protocol for systematic reviews. The second section, describes an overview of existing recommender systems in literature. The outline of this study is explained, as well as the method of content analysis used in this article to sort out the papers is introduced in the third section. In the fourth section, the selection process and the literature review matrix are provided. Additionally, the evolvement of research on crop recommendation over the years is considered, a detailed study of the main input features is done. Further, the current challenges found in crop recommendation are listed. The fifth section discusses the outcomes of the study. The last section recapitulates the outcomes of the study, shedding the light of research perspectives worthwhile pursuing.

\section{Introduction}

Crop selection (CS) is one of the most critical elements that affects the final yield directly, hence, selecting an appropriate crop is always a critical decision that a farmer ought to make, taking into account environmental factors. Choosing an appropriate crop for a given farm is a difficult decision including a plethora of variables that influence the final yield. Experts are frequently consulted to assist farmers with CS or Crop recommendation (CR); but, as this alternative is time consuming and expensive, it is not available and affordable for many farms.

The use of recommender systems (RSs) in agricultural management has recently brought some captivating and promising results, it has experienced a huge growth for their enormous benefits in supporting user's needs, through finding the most suitable items based on information extracted from a collection of data. These systems also play an important role in decision-making, helping users to maximize profits or minimize risks, e.g., Amazon store. Today, RSs are used in many digital companies, such as: Google, Yahoo, Netflix, etc., they are applied in different areas, such as: healthcare systems, education, customer segmentation, fraud detection, and financial banking [1].

RSs are being used in CR to provide farmers with better decisions. However, the CR field does not have a detailed classification scheme for its algorithms and features, mainly due to the diverse approaches proposed in literature, as well as the absence of an SLR dedicated to this issue, where most studies reviewed only the use of machine learning ML in crop yield prediction $[2,3]$. Therefore, it's difficult and confusing to choose a RS algorithm and input parameters that fit one's need, when developing a crop RS. In addition, researchers may find it challenging to track the use and the trends of RSs algorithms in agriculture. For these reasons, this SLR comes to fill the aforementioned gap the best possible. We decided to present a fair, unbiased, and credible SLR, that identifies all relevant and high-quality studies addressing the integration of RSs in CS with the following main objectives:

- Identify trends of RSs algorithms in CR.

- Classify the main techniques that were used in CR.

- Classify the main input features.

- Identify evaluation criteria and evaluation approaches that have been used.

- Specify the current challenges.

This paper is organized as follows: Section 2 gives a general overview of RSs. Section 3, presents the SLR's protocol. In section 4, an analysis of the results is provided for CR. Section 5 covers a discussion of the current achievements and current challenges. Finally, we conclude the analysis and present our future work.

\section{Overview Of Existing Recommender Systems}

The objective of a recommender system is to provide the user with relevant recommendations according to their preferences. It drastically reduces the time it takes for the user to search for the items that are most interesting to them, and also to find items that they are likely to like but that they might not have paid attention to. Recommendation systems have been defined in several ways. The most popular and general definition that we quote here is that of Robin Burke [4], which is as follows: "a recommender system is a system capable of providing personalized recommendations or of guiding the user to interesting or useful resources within a large data space". The information domain for a general recommendation system consists of a list of users who have expressed their preferences for various items. A preference expressed by a user for an item is called a rating, and is often represented by a triplet (user, item, rating). These notes can take different forms. However, most systems use ratings in the form of a scale of 1 to 5 , or binary ratings (like/dislike). The set of triples (user, item, note) form what is called the note matrix. The pairs (user, item) where the user did not give a score for the item are unknown values in the matrix. Firstly, there is non-customized recommendation systems that do not depend on the user for making recommendations. In non-customized recommendation, the used algorithms are: Top Popular, which recommends the top items (e.g., movies) with the highest ratings, and Product Association, which recommends the best combinations of items that are frequently bought together [5].

Customized approaches are other techniques that provide a recommendation to users based on ratings or content information. All these techniques are either focused on characteristics of an individual (or group) or characteristics of the product or service they are buying for example. In customized RS the following methods are used:

Knowledge-based (KB) filtering is a technique that employs explicit knowledge to identify user's preference based on knowledge of items, user, and matching between both. It is specifically effective in cases with less data on activity history of users [6].

RSs that are based on demographic information of users suggest a list of items that have good feedback from the users that are demographically similar [7]. The advantage of a demographic technique is that it does not require a history of user's feedback. 
The vast majority of prior research had adopted the collaborative filtering (CF) approach, which employs a family of algorithms that calculates the utility and the rating of an item for a given user. Two general classes as illustrated in Figure.1 were suggested in literature [8], Memory-Based (MB) algorithms, where the predicted value is estimated as a simple linear combination of ratings and weights, either explicitly or implicitly. The weights can reflect distance, correlation, or similarity between either users or items, this similarity function is the hyper-parameter that affects mainly the prediction quality. Several authors adopted Pearson, Euclidean and Cosine functions as similarity criteria, others used the development of genetic algorithms to find the most suitable combination of weight vectors $[9,10]$. Typical examples of this approach are neighborhood-based CF and item-based/user-based top-N recommendations.

MB algorithm are not always as fast and scalable as they are meant to be, especially in the context of actual systems that generates real-time recommendations based on very large datasets. To achieve these goals, MB RSs are used. MB CF involves building a model based on the dataset of ratings. In other words, Information is extracted from the dataset, and have been used as a "model" to make recommendations without having to use the complete dataset every time. This approach potentially offers the benefits of both speed and scalability. Two methods are generally used, one deals with the task from a probabilistic perspective, either by the calculation of the expected value of a rating given the user's historical data, or using dimensionality reduction techniques, such as: matrix factorization (MF); in order to model the latent factor space and user/item interactions. In the same context, a large number of existing studies in literature have examined the possibility of exploiting deep neural networks (DNN) architectures [11, 12, 13, 14], Convolutional Neural Networks [15, 16], Recurrent Neural Networks [17] and Auto-Encoders [18, 19]. To capture more complex and nonlinear relations above the ratings dataset, there are many MB CF algorithms. Bayesian networks, clustering models, latent semantic models, such as: Singular Value Decomposition (SVD), Probabilistic Latent Semantic (PLS) analysis [20], Multiple Multiplicative Factor (MMF), Latent Dirichlet Allocation (LDA) [21] and Markov Decision Process (MDP) based models that includes Contextual Bandits approach [22, 23] and Reinforcement Learning (RL) [24].

Nonetheless, CF algorithms suffer from three common problems, namely:

- Cold start reflects the inability of suggesting recommendation to a new user or item due to data absence.

- Sparsity problem occurs when available data are insufficient to identify similar users.

- Scalability problem happens when the RS's performance and latency decrease drastically with an increase in the number of users and items of the system.

And finally, one way to transcend these hassles is the combination of CF and Content-Based Filtering (CBF) methods, which are another family of algorithms that makes recommendations based on user preferences of product features, in a Hybrid Filtering (HF) technique [25, 26].

Due to the successful use of RSs in various advertisement sectors, they have been applied to solve a variety of problems in the agricultural sector. In [27] authors proposed an ontology based on an RS that helps to identify the pests affecting a crop and their treatments. In [28] a cultivation calendar RS for wheat cultivation in Egypt based on climate data is developed. In another work [29], a hybrid technique for recommendation of agricultural products to buyers is used. In [30] a CF web-based RS was designed to provide help, such as: financial help, irrigation facilities and insurance to the farmer's crops.

$\mathrm{CS}$ is one of the fundamental issues that have a strong influence on farmer's revenue, and the applications of recommendation techniques has shown a significant progress recently, especially for these specific tasks. Henceforth, the remainder of this analysis will focus on scientific papers CR.

\section{Research Formulation}

To present a clear review of the recommendation techniques applied in agriculture, we followed the SLR protocol adopted in PRISMA [31], in its latest version (2020). In the following sections we formulate the Research Questions (RQs) which we will try to respond in this SLR, then, we explain the adopted search strategy for collecting papers, followed by the exclusion criteria that serve as a filter to select relevant papers for review, and finally in the data extraction phase, the information needed for the analysis of the selected papers is extracted.

Questions Formulation

In order to accomplish the objective of this SLR and get a full analysis of CR techniques, we defined the following RQs:

- RQ1. How did research about CR evolved over time?

- RQ2. What are the main techniques used in literature for CR?

- RQ3. What are the main input features exploited for CR?

- RQ4. Which evaluation parameters and evaluation approaches have been used?

- RQ5. What are the current challenges in CR?

Search strategy 
To identify relevant studies, we first started by performing a selection of the major scientific databases, such as: Google Scholar, ACM, Springer Link, IEEE, Wiley, Emerald, etc.

There are some synonyms that indicate CR Systems. In this SLR, we con- sider terms that replace "recommendation" by "selection" or "suggestion". To retrieve studies that use new techniques that are based on agricultural data, we used the terms "Artificial Intelligence”, "Machine Learning", "Deep Learning”. All these terms were featured in the Search Query (SQ), which is presented as follows:

Query = (Crop AND (Recommendation OR Selection OR Suggestion) AND ("Artificial intelligence" OR "Machine Learning" OR "Deep Learning"))

Exclusion criteria (EC)

To strengthen the validity of the SLR, we considered only studies published between 2010 and 2020, and we maintained those that have no evaluation section due to the lack of research publications about the CR field. We adopted the following EC:

- EC1. Studies must be peer-reviewed articles or proceedings.

- EC2. Studies must be published in a conference, journal, press, etc.

- EC3. Letters, notes, and patents are not included in the review.

- EC4. Graduate reports are not considered for review.

- EC5. We considered only studies in English.

- EC6. Studies that do not describe their proposed approach in a proper way were not considered in the review.

Data collection process

To answer the aforementioned RQs, data from the selected articles have been collected and structured. The extracted information focused on verifying whether the studies meet the requirements stated in the exclusion criteria section or not. The redeemed information are as follows:

- Paper reference.

- Year and type of publication.

- The Indexing Database.

- The country origin of study.

- Models used to address the problem.

- The inventory and description of crops and features used in each study.

- Performance measures used to evaluate the proposed models.

\section{Results Of The Study}

This section presents the harvest of the selection process. Then, we present the information matrix along with results of each RQ.

Criteria selection

Based on the obtained results from the aforesaid scientific databases, 89 results were identified. We followed a filtering process to eliminate the articles that do not match our selection criteria. We first excluded 18 records because they were not indexed in well-known academic indexing services. Afterwards, we started scrutinizing the articles' content by reading the title, abstract and keywords, after that we kept 50 articles for further investigation, in addition to 2 more articles that were found in references. By full reading of the 52 articles of this study, we excluded another 12 articles, as they are either not clearly relevant, or are out of our scope. Thus, we ended up with 40 papers for synthesis and analysis. Fig 2 illustrates a flow chart of the paper filtering process. 
One of the major problems that the farmers face in the beginning of every agricultural season is the selection of a suitable crop that would produce a better yield. This process is usually done based on the farmer's experience, or with the help of an agronomist. Assisting this process was the objective of a huge number of papers throughout the past few years. Table 1 below puts forward the LRIM presenting in detail the studied articles that addressed this problem, based on different approaches and techniques.

Table 1. Literature Review Information Matrix (LRIM) 


\begin{tabular}{|c|c|c|c|c|c|c|c|}
\hline Referen & eYear & Contribution & Dataset & $\begin{array}{c}\text { Models } \\
\text { \&techniques }\end{array}$ & Strengths & Weaknesses & Performance \\
\hline [32] & 2014 & $\begin{array}{l}\text { In this paper, a } \\
\text { Multi-Level } \\
\text { Linguistic Fuzzy } \\
\text { Decision Network } \\
\text { (LFDN) method } \\
\text { is applied to a } \\
\text { real case dataset } \\
\text { to decide the } \\
\text { cultivate crop } \\
\text { among four } \\
\text { crops. }\end{array}$ & $\begin{array}{l}\text {-Crops: Wheat, Corn, Rice, } \\
\text { and Faba bean. } \\
\text {-Features: } \\
\text { Temperature, Water, } \\
\text { Marketing and Soil. }\end{array}$ & $\begin{array}{l}\text { Multi-Level } \\
\text { LFDN. }\end{array}$ & $\begin{array}{l}\text { The method can } \\
\text { rank the } \\
\text { actions/alternatives } \\
\text { to select the } \\
\text { appropriate } \\
\text { alternative. }\end{array}$ & $\begin{array}{l}\text { The dataset used was not } \\
\text { described. }\end{array}$ & $\begin{array}{l}\text { No performance metric was } \\
\text { used. }\end{array}$ \\
\hline [33] & 2014 & $\begin{array}{l}\text { This work } \\
\text { Integrated } \\
\text { artificial neural } \\
\text { networks (ANN) } \\
\text { with geo- } \\
\text { graphical } \\
\text { information } \\
\text { system (GIS) to } \\
\text { assess the } \\
\text { suitability of land } \\
\text { to cultivate a } \\
\text { selected crop. }\end{array}$ & $\begin{array}{l}\text {-Crops: Rice. } \\
\text {-Features: Rainfall, } \\
\text { Temperature, Elevation } \\
\text { and Slope. }\end{array}$ & $\begin{array}{l}\text { ANN, } \\
\quad \text { and } \\
\text { Back- } \\
\text { propagation. }\end{array}$ & $\begin{array}{l}\text { High consistency in } \\
\text { predicting crop suit- } \\
\text { ability map. }\end{array}$ & $\begin{array}{l}\text { Only } 4 \text { parameters were used to } \\
\text { assess the suitability of the } \\
\text { crop. }\end{array}$ & $\begin{array}{l}\text {-Mean squared error } \\
\text { (MSE): } 0.113 \\
\text {-Accuracy: } 83.43 \%\end{array}$ \\
\hline
\end{tabular}

[34] 2015 selected crop.

This paper -Crops: Seasonal crops, presents a Whole year crops, short technique named time plantation crops and CS method to longtime plantation crops. select a sequence -Features: of crops based on Geography of a region, crop proprieties Weather conditions, Soil to improve net type and Soil texture. yields rate of crops to be planted over a season.

[35] 2015 In this paper, a rule system is developed to help farmers make decisions about the choice of rice varieties using the crop and the properties.

[36] 2016 In this article a hybrid soft decision model has been developed to take $\begin{array}{ll}\text { decisions on } & \text { input (6 sub criteria), } \\ \text { agriculture crop, } & \text { support, facilities, and risk. }\end{array}$ that can be cultivated in each experimental land.

[37] 2016 The proposed system is designed to predict the best suit- able crops for a given farm, and to suggest farming strategies, such as: mixed cropping, spacing, irrigation, seed treatment, etc. along with fertilizers and pesticides.

[38] 2016 The authors applied the majority voting technique using Random tree CHAID, K-nearest neighbors (KNN) and Naïve Bayes as base learners for CR.

[39] 2017 Proposed a system that can detect the user's location then recommend top-k crops based on the seasonal information and crop production

Crops: 118 rice varieties.
-Crops: Millet, groundnut, pulses, cotton, vegetables, banana, paddy, sorghum, sugarcane, coriander. -Features: Depth,

Texture, pH, Soil Color,

Permeability, Drainage,

Water holding and Erosion. -Features: Crop Growing period database, Thermal zone database, Physiographic database, Seasonal crop database and CPR database.
-Crops: Not mentioned.
CSM.

CSM method possible crops that are to be sown at a given time stamp.
Features: 7 Features.

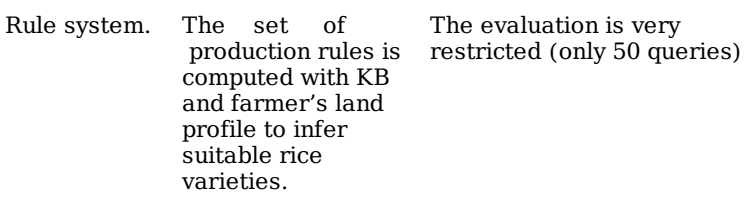

The evaluation is very restricted (only 50 queries)

-Crops: paddy, groundnut, sugar- cane, cumbu and

ragi. -Features: Twentyseven input criteria

namely soil, water, season,
input (6 sub criteria) support, facilities, and risk.

\section{-Crops: 44 crops that have been considered.} -Features: Crop

name, suitable rain- fall temperature, cost, soil, and $\mathrm{pH}$.
Shannon's The model used entropy deals with method and incomplete VIKOR / /missing data and method. inconsistency problems.
ANN and The extraction of fuzzy logic (FL). using FL.
More agricultural parameters can be identified to be included in the system.
No evaluation metrics or experiments have been applied to precise the efficiency of the proposed system. used. $\begin{array}{ll}\text { The model is trained (150) and } & \text {-Accuracy: } 95.2 \% \\ \text { tested (25) in a small dataset. } & \text {-Precision: } 88.66 \%\end{array}$
-Precision: $34 \%$ of crops had a value from 0 to 0.2 and $30 \%$ from 0.8 to 1 . -Recall: $39 \%$ of crops had a value from 0 to 0.2 and $40 \%$ from 0.8 to 1 .
Ensemble, Large number of Naive Bayes, soil attributes are Random tree, used for the CHAID and prediction KNN.

Pearson correlation similarity (PCS).
The developed system can recommend appropriate crops in a satisfactory way.
Fertilization data like NPK values present in soil are not used.
Accuracy: $88 \%$
The model doesn't take into consideration the existing nutrient in the farms soil.
-Precision: 72\% -Recall: 65\% 
rate $(\mathrm{CPR})$ of

each crop of

similar farms.

[40] 2017 In this article, an at- tempt is developed to predict crop yield and price that a farmer can obtain from his land patterns in past patter.

[41] 2017 In this study, a FL- based expert system is proposed to automate the CS for farmers based on parameters, such as, the climatic and soil conditions.

[42] 2017 In this paper, a decision-making tool is developed for selecting the suitable crop that can be cultivated in each agricultural land.

[43] 2017

This paper develops a fuzzy based agricultural decision support system which helps farmers to make wise decisions regarding CS

[44] 2017 This paper proposed two mathematical formulations, the first one for the determination of crop-mix that maximizes the farmer's expected profit, and the second model that

maximizes the average expected profit under predefined quantile of worst realization

This paper Suggested using deep neura network for agricultural CS and yield prediction. system for CR based on an ensembling technique.

[47] 2018 This paper presents an intelligent system, called Agro-Consultant, which assists farmers in making decisions about which crop to grow.

[48] 2018 This paper Investigated the predictive

\section{rops: Not mentioned. \\ -Features: Crop areas types of crops cultivated,}

nature of the soil, yields

and the overall crops

consumed.

Crops: 20 crops.

Features: 23 features.

Fuzzy
based
expert
system.

Non-linear
regression

The developed system uses the demand as input.

The recommendation model is not tested or evaluated on a used.

dataset.
The study uses an of features to select the suitable crop.
The proposed system is extremely customizable in of a more ad hoc system.
-Crops: Paddy, groundnut, and sugar- cane. -Features: 26 input variables were classified into six main variables, namely soil, water, season, input, support, and

infrastructure.

-Crops: Not mentioned. -Features:15 parameters.

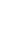
Barley.

-Features: the land available to grow crops,

the sequence of operations required for each crop, the corresponding time

windows, the avail- ability of tools and tractors, their operating costs and the working speeds.
Decision

matrix,

Dominance-

based rough

set

approach

and

Johnson's

classifier.

Mamdani

Fuzzy

Inference

System.
The validation results showed that metric to evaluate the model.

the developed tool

has a sufficient

predictive power to

help the farmers to

select suitable

crop.

The system is deployed at many

places and results

are found to be

accurate.

of the model.
Natural The proposed

Integer

Programming

and

Maximization

of the

Conditional

Value-at-Risk

(CVaR).

increments the

worst outcomes model significantly testing, and the model could be is higher than the farmers.

enriched by incorporating

explicit decisions about other

used.

No empirical study was $\quad$ No performance metric the quality used.
-Crops: Aus rice, Aman

rice, Boro rice, Jute,
Wheat, and Potato.

46 parameters
DNN,

Logistic

Regression,

Support

Vector

Machine

(SVM) and

Random

Forest (RF).

-Crops: Cotton,

Sugarcane, Rice,

Wheat.

Features: Soil

Type, $\mathrm{pH}$ value of

the soil, NPK

content of the soil,

Porosity of the soil

Average rainfall

Surface

temperature

Sowing season.

-

Decision Tree

(DT), KNN, RF and

Type, Soil pH,

Precipitation,

Temperature,

Location

parameters.

-Crops: Not

mentioned.

-Features: $\mathrm{pH}$
Ensembling Model Using three different and

(RF, Naive Bayes and

Linear SVM and

technique). predictions.
The proposed

model has a

relatively high

accuracy.
Lack of details about the

the complete list of input

parameters. parameters of the model and

Accuracy $\geq 90 \%$

Only four crops were used for

Accuracy: 99.9: train and test.

A Map View feature, where the

Not considering other economic Accuracy: 91\% farmers can view the sow decisions indicators like farm harvest made by his neighboring farmers prices and retail prices. using a pop-up marker on the map.

J48, BF tree, OneR

Comparison of the performance of four classification algorithms.
Recommending a class of crops instead of recommending a single crop.
-Accuracy: 97\% -Precision: $97 \%$ -Recall: 97\% 
performance of

mining

classification

algorithms to

recommend the

best crop for

better yield

based on a

classification of

soil under

different

ecological zones.

[49]

2018 The article

proposes a

system that gives

the farmer a

prior idea

regarding the

yield of a

particular crop by

predicting the

pro- duction rate

according to the

location of the

farmer and the

past data of

weather

conditions.

[50] 2019 This study

proposed to

design a $\mathrm{KB}$

solution for

building an

inference engine

for

recommending

suitable crops for

a farm.

[51] 2019 A new datamining

technique was

proposed to

proposed to
cluster crops

cluster crops
based on their

suitability

compared to soil

nature of

different areas.

[52] 2019 In this paper, a

multi-class

classification-

based decision

model has been

developed to

assist the farmer

in selecting

suitable crops

using rough,

fuzzy, and soft

set approaches.

[53] 2019 This study

proposes an

intelligent

agriculture

platform that

manages and

analyses sensors

data to monitor

environmental

factors, which

provides the

farmer a better

understanding of

crop suitability.

[54]

2019

This paper

suggests the

using of ANN and

SVM for crop

prediction

considering the

environmental

parameters.

[55] 2019 The paper

proposes a

mobile

application that

will allow

farmers to

predict the

region's

production for a

specific crop.

[56] 2019 This study

applies learning

-Crops: Rice, corn

and soybeans.

Organic Matter, K,

$\mathrm{EC}, \mathrm{Zn}, \mathrm{Fe}, \mathrm{Mn}, \mathrm{Cu}$

and texture.

-Crops: Rice.

Features:

Temperature,

humidity, location,

and rainfall.

crop, temperature,

sugarcane, cumbu

vector

type, temperature,

Mamdani Fuzzy

model and Cosine

similarity (COS).

Relying only on location and weather parameters for prediction.

The study focused only on rice pro- duction and has not considered the other climatic conditions.

-Crops: Not

mentioned.

-Features:

Elevation,

temperature,

tilizer type,

reenfall, field type,

-Crops: 10 Crops.

Features: Soil, and rainfall.

-Crops: Paddy, groundnut, and ragi.

-Features: 27 features.

-Crops: Celery water spinach

green beans, and

daikon.

-Features:

Temperature,

humidity,

illumination,

pressure, soil

electrical

conductivity (EC),

soil moisture

salinity.

-Crops: Not

mentioned.
PART Rule Based

Classifier and

expert's knowledge.
The model developed has the potential to increase the accuracy of KB system (PART Rule algorithm).

Various datasets were merged to extract crops requirements.

Hierarchical

clustering.

\section{Dominance-based} rough, Grey

relational analysis,

Fuzzy proximity

relation, Bijective soft

set approach, Naive

Bayes, SVM and J48.

Moving average, autocorrelation, and 3D cluster correlation.

-Features: Rainfall minimum and maximum

temperature, soil type, humidity, and soil $\mathrm{pH}$ value.

-Crops:

mentioned.

-Features: Soil rainfall.

Not

ARIMA method, linear An android application was regression (LR), SVR model.
The validation test outputs were
com- pared to agricultural experts.
The system ensures a better understanding of the environmental factors behavior and analyses the farmer actions, such as application of fertilizer or pesticide, it also takes global warming into consideration.

\section{ANN and SVM.}

An interface was designed to enable the access to necessary information for selecting the proper crop.

developed to facilitate the farmers accessibility to the suggested model.

Only five crops were used.

Ony Ten crops in eight different used for prediction and evaluation.

The evaluation in this study is done by un- known experts.

-Farmers Accu -Domain expe Accuracy: 95.2: Agricultural ex 1 Accuracy: 88.5 cording to the study, the model is relatively slow.

The application of the system analysis result isn't automotive and no artificial intelligence model was used.
Test evaluation was done by comparing the predicted crop with the real ones, which not accurate since the actual cultivated crop isn't necessarily the optimal.

The white noise for ARIMA model was chosen as a random value in the range of $0 \%$ to $10 \%$ of the crop yield.
Comparis on of the evaluation metric between expert

recommendation and real data.
Only three crops were used, rice, corn, soy- bean.

No performanc used.

No performanc was used.

-Accuracy: 98. -Precision: 92\%

No performanc was used. 
quantization

(LVQ), which is

part of the ANN

method, to

provide

recommendations

from three

types of plants.

alone crop

recommending

device that

detects soil

quality and

recommends a

list of crops

based on a FL

models.

[58] 2019 This paper

presents a hybrid

mentioned.

crop RS based on -Features:

a combination of Temperature data

a CF technique rainfall, solar

and a case-based radiation, wind

reasoning. speed,

evaporation,

relative humidity,

and

evapotranspiration.

[59]

his work

proposes a model mentioned.

that can predict

soil series with

land type,

according to

which it can

suggest suitable

crops.

[60] 2019 The article

addressed the

problem of

selection of best

suitable crop for

a farm, by

applying different

classification

algorithms.

[61] 2019 This work

-Crops: Not

ontology-based -Features: Soil

recommendation characteristics,

system for crop weather conditions suitability and crop

recommendation production.

based on region

and soil type.

proposed a

-Crops: 24 Crops.

-Features: 15

hybrid RS based Features.

on two

classification

algorithms by

considering

various

[63] 2020 attributes.

The article

proposes using mentioned.

hierarchical fuzzy -Features: Sand,

model to reduce silt, clay, nitrogen,

the classical phosphorus,

system potassium, soil

complexity with color, soil $\mathrm{pH}$, soil

the huge number electrical

of generated conductivity,

rules. rainfall, climate

[64] 2020 This work resources

developed an Pear, Apricot, and

application that Almond.

helps selecting

the most

convenient type

of crops in a

certain zone

considering the

climate

condition

zone, the

production, and

the needed

resources for

each crop.

[65]

proposed an

FL

Stand-alone device gives faster and less details about the model and real-time soil property reading and it's performance. crop suggestion.

No performanc used.

Only weather parameters were considered.

remarkable performance and rational accuracy of prediction.

Reasoning (CBR)

Suggesting crops based only on Class of soil series is very

Weighted KNN, aussian Kernel based SVM, and Bagged Tree.

SVM, DT and Logistic regression.

The authors compared different models.

The accuracy of the developed system is reasonably high.

The model was evaluated using Multiple Performance metrics.

Farmers cannot lo- cate their exact coordinates. model.

Only 4 parameters were considered from CR.

Precision: $90 \%$ Recall: 93\%

The best perfo] $89.66 \%$ and wa using the SVM

Precision: $65 \%$

-Accuracy(J48) :
-Recall(

F-Measure(J48

zone, and water

Hierarchical fuzzy model.

\section{Fuzzy system.} Features: Relative humidity, Radiation, Wind speed,

Temperature, Wind direction, Cooling units, Sunlight,

Rainfall,

Accumulated

radiation, and Wind run.
The number of generated rules were reduced from 439 to only 152
No evaluation metrics are provided.
No performanc was used.
The farmer's recommendation request is made using internet of things (IoT) devices.
The recommendation module can be scaled to consider other types of additional information like soil parameters.
The performance is measured The suggested method can using different evaluation metrics. be tested with a wide set of
-Accuracy: 92\%

Precision: 93\% 


\begin{tabular}{|c|c|c|c|c|c|c|c|}
\hline & & $\begin{array}{l}\text { implementation } \\
\text { of a fuzzy-based } \\
\text { rough set } \\
\text { approach to help } \\
\text { farmers in } \\
\text { deciding on CS in } \\
\text { their agriculture } \\
\text { land. }\end{array}$ & $\begin{array}{l}\text {-Features: } 16 \\
\text { Features. }\end{array}$ & & & new crops. & $\begin{array}{l}92 \% . \\
91 \%\end{array}$ \\
\hline [66] & 2020 & $\begin{array}{l}\text { This work } \\
\text { proposes a CR } \\
\text { system according } \\
\text { to multiple } \\
\text { properties of the } \\
\text { crop and land. }\end{array}$ & $\begin{array}{l}\text {-Crops: } 24 \text { crops. } \\
\text { Features: Soil } \\
\text { types, pH, Electric } \\
\text { Conductivity, } \\
\text { Organic Carbon, } \\
\text { Nitrogen, } \\
\text { Phosphorus, } \\
\text { Sulfur, Zinc, Boron, } \\
\text { Iron, Manganese } \\
\text { and Copper. }\end{array}$ & Property matching. & Fast and simple algorithm. & $\begin{array}{l}\text { Only soil properties were } \\
\text { considered as in- put to the } \\
\text { model. }\end{array}$ & $\begin{array}{l}\text {-PCS: } 4.80 \% \\
\text {-COS: } 6.45 \%\end{array}$ \\
\hline [67] & 2020 & $\begin{array}{l}\text { This paper } \\
\text { proposes a CS } \\
\text { method to } \\
\text { maximize crop } \\
\text { yield based on } \\
\text { weather and soil } \\
\text { parameters. }\end{array}$ & $\begin{array}{l}\text {-Crops: } 10 \text { Crops. } \\
\text { - } \\
\text { Features: Soil type, } \\
\text { soil nutrients, soil } \\
\text { pH value, Drainage } \\
\text { capacity, weather } \\
\text { conditions. }\end{array}$ & $\mathrm{RF}$ & $\begin{array}{l}\text { The soil and predicted weather } \\
\text { parameters are used collectively to } \\
\text { choose suitable crops for land. }\end{array}$ & $\begin{array}{l}\text { Only Four soil parameters were } \\
\text { considered. }\end{array}$ & $\begin{array}{l}\text { No performanc } \\
\text { was used. }\end{array}$ \\
\hline [68] & 2020 & $\begin{array}{l}\text { This study } \\
\text { Proposes a } \\
\text { clustering center } \\
\text { optimized } \\
\text { algorithm by } \\
\text { SMOTE, then use } \\
\text { an ensemble of } \\
\text { RF and weighed } \\
\text { SVM to predict } \\
\text { the } \\
\text { recommended } \\
\text { crop. }\end{array}$ & $\begin{array}{l}\text { The data } \\
\text { includes } 1530 \text { soil } \\
\text { samples and } \\
13 \text { types of } \\
\text { cultivated land } \\
\text { crops. }\end{array}$ & RF and SVM. & $\begin{array}{l}\text { Classification of crops based on } \\
\text { soil analysis }\end{array}$ & $\begin{array}{l}\text { The study reference range is } \\
\text { limited. }\end{array}$ & $\begin{array}{l}\text {-Accuracy: } 98 . \\
\text { Precision: } 97.4 \\
\text { Score: } 97.8 \% .\end{array}$ \\
\hline [69] & 2020 & $\begin{array}{l}\text { This paper treats } \\
\text { the integration of } \\
\text { AHP and } \\
\text { POPSIS with } \\
\text { GIS to determine } \\
\text { most suitable } \\
\text { crops for parcels } \\
\text { for land } \\
\text { consolidation } \\
\text { areas. }\end{array}$ & $\begin{array}{l}\text {-Crops: Corn, } \\
\text { Clover, Sugar beet } \\
\text { and Wheat. } \\
\quad \text {-Features: } \\
63 \text { Land Map Units } \\
\text { and their chemical, } \\
\text { physical, } \\
\text { topographical, and } \\
\text { socio-economic } \\
\text { features. }\end{array}$ & $\begin{array}{l}\text { Analytic Hierarchy } \\
\text { Process (AHP), } \\
\text { Technique for Order } \\
\text { Preference by } \\
\text { Similarity to Ideal } \\
\text { Solution (TOPSIS). }\end{array}$ & $\begin{array}{l}\text { The integration of AHP, TOPSIS } \\
\text { and GIS functions provide an } \\
\text { effective platform to determine the } \\
\text { suitability. }\end{array}$ & $\begin{array}{l}\text { Several criteria can be added } \\
\text { such as meteorological and } \\
\text { irrigation. }\end{array}$ & $\begin{array}{l}\text { No performanc } \\
\text { used. }\end{array}$ \\
\hline [70] & 2020 & $\begin{array}{l}\text { This article } \\
\text { proposes a } \\
\text { system for } \\
\text { predicting the } \\
\text { crop which has } \\
\text { maximum yield } \\
\text { per unit area in a } \\
\text { district. }\end{array}$ & $\begin{array}{l}\text {-A dataset } \\
\text { published by the } \\
\text { Government of } \\
\text { Maharashtra, } \\
\text { India, containing } \\
\text { approximately } 246 \\
100 \text { data points. }\end{array}$ & $\mathrm{RF}$ & $\begin{array}{l}\text { The algorithm works even when } \\
\text { the variables are mostly } \\
\text { categorical. }\end{array}$ & $\begin{array}{l}\text { The performance could be much } \\
\text { better when considering more } \\
\text { variables. }\end{array}$ & $\begin{array}{l}\text { Normalized Ro } \\
\text { Squared Error } \\
49 \% \text { (median v }\end{array}$ \\
\hline & & & $\begin{array}{l}\text { Features: } 7 \\
\text { parameters on the } \\
\text { time span } 1997 \text { to } \\
2014 \text {. }\end{array}$ & & & & \\
\hline [71] & 2020 & $\begin{array}{l}\text { This article } \\
\text { suggests a FL- } \\
\text { based CR system } \\
\text { to assist farmers } \\
\text { in selecting } \\
\text { suitable crops. }\end{array}$ & $\begin{array}{l}\text {-Crops: Paddy, } \\
\text { Jute, Potato, } \\
\text { Tobacco, Wheat, } \\
\text { Sesamum, Mustard } \\
\text { and Green gram. } \\
\text {-Features: } 11 \\
\text { soil parameters, } \\
\text { elevation and } \\
\text { rainfall. }\end{array}$ & FL & $\begin{array}{l}\text { the validation was based on a } \\
\text { Cultivation Index (CI). }\end{array}$ & $\begin{array}{l}\text { No explanation of how the } \\
\text { member- ship functions of the } \\
\text { inputs and outputs were derived } \\
\text { from the dataset. }\end{array}$ & Accuracy: 92.1 \\
\hline
\end{tabular}

How did research about CR evolved over time?

The uprise of new technologies in solving agricultural problems is an imminent fact. We can see in Figure 3a the distribution of selected studies over time, and we notice a remarkable increase in the number of studies related to CR from 2014 to 2020 . Figure $3 \mathrm{~b}$ illustrates the distribution of papers based on source database. Most of the selected papers were published in IEEE or Springer, and fewer papers were found in Wiley database. Furthermore, Figure $3 c$ presents the proportion of each type of publication, nearly $62 \%$ of papers were published in imminent conferences, and about $31 \%$ comes from journal issues, while only $7.14 \%$ are book chapters, which enforce the quality of the publications included in the SLR. 
RSs are generally classified into three types: CBF, CF, or HF. The CF based model was used the most in our literature review, as discussed in section 2, CF tries to compress the entire database into a model, then performs its recommendation task by applying reference mechanism into this model. We identify two common approaches for MBCF: clustering and classification. Clustering CF assumes that users of the same group have the same interest, so they are partitioned into groups called "clusters". The authors in [61] proposed K-means clustering (KMC) algorithm, which is an unsupervised learning algorithm used to find out fertilizers with NPK contents that are the nearest to the requirements of a specific crop. First it calculates the required amount of the fertilizer, then the algorithm forms clusters of nearby fertilizers based on the Euclidean distance. Therefore, fertilizers in clusters with minimum distance are recommended to farmer. The recommendation task can be viewed as a multiclass classification problem, which uses a classifier supervised learning algorithm that maps the input data to a specific output, a variety of these classifiers were tested on agricultural data. In this context, this study [48] carried out a comparative experiment on data instances from Kasur district, Pakistan for soil classification using J48, BF Tree and OneR, that are a variety of DT based models, which is the most used technique in our literature survey. Besides Naive Bayes Classifier (NBC) that has a significant outcome, mainly because it encodes dependencies among different features by which it connects the causal relationships between items. On the other hand, [54] has investigated the use of SVM and ANNs. The results indicate that the ANN model captures non-linearities among features of the dataset, marking the best accuracy and prediction rate compared to SVM. Another technique for CS that can improve the model's accuracy is ensemble learning, [46] exploited this technique in order to build a model that combines the predictions of multiple ML algorithms together and recommend the right crop with a high accuracy. The independent base learners used in the ensemble model are RF, NBC, and Linear SVM. Each classifier provides its own set of class labels with an acceptable accuracy. The labels class of individual base learners are combined using the majority voting technique. The CR system classifies the input soil dataset into the recommendable crop type, Kharif and Rabi (Autumn and Spring). One of the most promising models in CF is FL, which extracts IF-THEN rules from the provided data using a membership function and linguistic variables that expresses the human knowledge. The authors in [49] proposed a fuzzy based model that uses 27 rules with 3 modalities: Low, Medium, and High. In this traditional single-layer fuzzy system, the rules are exponentially increased when the system's parameter increased, and a larger rule base will affect the system performance and transparency. Therefore, [63] developed a multi-layer system by using the fuzzy hierarchical approach. The hierarchical fuzzy model was applied in the same Mamdani[1] fuzzy inference system for a suitable CR system. The CR system has 12 input variables, and it was decomposed into six fuzzy subsystems, then arranged by priority. The results show that a hierarchical CR system provides a better performance than a traditional fuzzy CR.

CFMB models have a low frequency in the reviewed studies, even though they represent the most common approach in RSs. Yield prediction is based on similarity relationships among items (farms or crops), in terms of collected production yield. For instance, [39] proposed a model consisting of calculating the PCS between farms using the information stored in the crop growing period database, the thermal zone database, and the physiographic database, then, they select the top $\mathrm{n}$ similar farms. The seasonal information and CPR of each crop of the similar farms are used for filtering the first appropriate list to the context. Finally, they recommend the top k crops to each user respectively. Another study [49] used the similarity approach, in which they developed a system that gives the farmer a prior idea regarding the yield of a particular crop, by predicting the production rate. The COS measure is used to find the similar farmers in terms of location from the database. Then, the resulting farmers that are like the querying farmer form the database for the fuzzy algorithm.

$\mathrm{CBF}$, one of the most significant models in RSs, which are of a high importance for CR, as well as yield estimation. Examples of CBF model applications included in [66], the model of this study is based on the contents that use soil and crop properties, then suggests the list of five high priority crops based on the corresponding properties between the crop and the land for matching soil properties. The algorithm takes two inputs, the land soil details and the re- quired property value for each crop. Primitively, the algorithm computes the similarity between the land and the crop, based on their properties to predefine a range. If the comparison falls in a predefined range, they generate a rank for the combination of crops and lands. In another study [51], authors developed a new data mining technique to cluster the crop based on the suitability of a crop against the soil nature of areas. Features are extracted from the datasets using five different feature extraction metrics, such as, pH distance calculation, NPK (Macro nutrition distance calculation), MICRONUT (Micro nutrition distance calculation), water requirements, and temperature requirements. Then, the crops are clustered using hierarchical clustering based on the vectors into three groups, namely: most suitable, less suitable, or least suitable.

HF is another significant category of models used in CR. In the first study [64], authors presented a new method, which is integrated within an loT system, that is developed to advise farmers which crop type will generate more yield. A fuzzy clustering technique is proposed to the obtained groups that have been characterized by their weather conditions. The extracted knowledge forms the model and the rules engine. Finally, the RS generates an ordered list of crops that are suitable in descending order. In the second study [37], the authors developed a CR (hybrid) system, which utilizes FL to choose from 44 crop rules. The system is based on FL, which gets input from an ANNs based weather prediction module. An agricultural named entity recognition module is developed using conditional random field to extract crop conditions data. Further, cost prediction is established based on a LR equation to aid in ranking the crops recommended.

Table 3 shows how many studies describe an approach in each of the classes described earlier in section 2, as well as the studies themselves according to the approach category. As an outcome, a significant number of CF approaches when developing RSs are observed. Over half of the reviewed studies indicated that CF is the most used approach, with a stronger emphasis on a MB method. Perhaps, the availability of historical datasets of farmers linked to the marked dominance of $\mathrm{CF}$ in the last years.

Figure 4 traces the timeline of publications, this latter confirms that CF with a MB method has a continual growth. The graph shows that there has been a slight increase in the two recent years in this field and the number of studies is likely to increase after 2020.

Another important conclusion drawn from Table 2 and Figure 4 is the scarcity of research efforts focused on other filtering methods. Nevertheless, some studies showed that the CBF and HF give more accurate recommendations overall than all other types of filtering. However, throughout the years, the research

Page $11 / 23$ 
pace on these types of filtering has been relatively low.

Table 2: Articles by type of recommendation technique.

\begin{tabular}{ccc}
\hline Classification of RS & Number of studies & References \\
\hline CF / Model-based & $\mathbf{2 8}$ & {$[32,33,34,38,40,41,42$,} \\
& $46,52,61,53,54,55,56$, \\
\hline & $59,47,63,57,69,62,68$, \\
& & $71,43,65,60,70,67,45]$ \\
\hline CBF & $\mathbf{5}$ & {$[35,48,51,66,44]$} \\
HF & $\mathbf{5}$ & {$[36,37,50,58,64]$} \\
CF/MB & $\mathbf{2}$ & {$[39,49]$} \\
\hline
\end{tabular}

Table 3 shows the distribution of applied ML algorithms in this study. Some papers applied more than one ML algorithm. Peculiarly, the most applied ML algorithm is DT-based. However, this SLR does not differentiate between different DT-based algorithms (J48, Part, RF, etc...) in the analysis. The other widely used algorithms are SVM and FL algorithms. Some ML algorithms had a low rank in this SLR despite their popularity. It is the case of the similarity methods or regression algorithms. Thus, these algorithms are not being investigated enough, which opens opportunities for future studies in $\mathrm{CR}$ field, to fill this gap.

According to our study, the most popular type of RSs in agricultural applications, is CF. A collaborative shift with a product-based focus is another name for this kind of algorithm. In this Filtering, users are filtered and associated with each User in place of things. Only users' behavior is taken into account in this system. Only their profile information and content are insufficient. Users who rate products favorably will be linked to other users who act in a similarly favorable manner.

Comparing CF to CBF, CF offers a variety of benefits. Among them are:

1. The item's content is not important for relaying the entire context.

2. If an item's information is not readily available, it is still possible to rate the item without having to wait to purchase it.

3. The user's preferences and aspects are not taken into account when the focus is on the content.

4. In order to determine the links between the buyers and to make the best proposal based on the similarities between the users, $\mathrm{CF}$ depends on the ratings of other customers. In contrast, the CB technique only requires a user's profile and goods to be examined.

5. Due to the fact that the majority of the unknown users share your preferences, CF provides ideas. However, in CB, you will receive item recommendations based on feature lists.

6. New goods are recommended by numerous users without any specifications, in contrast to CF.

7. The biggest issue with $\mathrm{CB}$ is the cold start, which appears when there are not many rating records in the recommendation system. In this situation, $\mathrm{CBF}$ is a great solution to the issue.

8. The term used in the text to represent the item may not be representative, which is one disadvantage of the CB approach. Making flawless recommendations to users based on the exact ratings is another drawback of this strategy.

The following list includes a number of CF's shortcomings:

1. The CB system is only an idea for a design that takes into account the user's current interests. As a result, one could also argue that this system is solely constrained by the interests or desires of current users.

2. This model only has outstanding hand setup features since the item representation of the features is hand-setup in comparison, which needs sufficient domain knowledge.

3. If the item's content is inadequate to accurately describe the item, the final suggestion will be erroneous.

4. Since the item and profile attributes must match, the CB approach offers nothing in the way of innovation. A great CBF technique must surprise you.

5. Strong user profile information must be entered into the system in order for the algorithm to deliver the correct recommendation.

6. Scalability is the main issue with the suggested CF solution. Given the site's growing user base, the system must offer the top user reliable suggestions. $\mathrm{CF}$ is a filtering method that is frequently used in systems that are suggested. Comparatively speaking to a CBF system, a CF system might inherently filter material that the system could not describe or evaluate, it may also suggest current information. The CF strategy is based on gathering and analyzing a lot of data regarding users' actions, interests, or conduct in order to predict what users will like based on their connections to other users. Itemto-item CF (those who buy $x$ also buy $y$ ), a method promoted by Amazon suggested system, is one of the most popular types of CF. 
Each approach, whether a CF system or a CBF system, has a number of advantages and disadvantages. As a result, many firms have adopted a hybrid system to combine the benefits of both methods, as previously discussed, and make every effort to offer their users more approachable and accurate advice.

Table 3: Number of articles by type of ML algorithm used.

\begin{tabular}{ccl}
\hline ML Algorithm Number of studies & References \\
\hline DT & $\mathbf{1 3}$ & $\begin{array}{l}{[38,52,48,47,46,61,59,50,68,} \\
60,70,67,45]\end{array}$ \\
& & {$[32,37,41,52,63,49,57,64,71$,} \\
FL & 11 & $43,65]$ \\
\hline SVM & $\mathbf{8}$ & {$[46,52,54,55,59,68,60,45]$} \\
\hline ANN & $\mathbf{6}$ & {$[33,37,54,59,58,45]$} \\
NBC & $\mathbf{4}$ & {$[38,46,52,48]$} \\
\hline Regression & $\mathbf{4}$ & {$[40,60,45,69]$} \\
\hline KNN & $\mathbf{3}$ & {$[38,59,47]$} \\
\hline Ensemble & $\mathbf{2}$ & {$[38,46]$} \\
\hline KMC & $\mathbf{1}$ & {$[61]$} \\
\hline PCS & $\mathbf{1}$ & {$[39]$} \\
\hline COS & $\mathbf{1}$ & {$[49]$} \\
\hline LVQ & $\mathbf{1}$ & {$[56]$} \\
\hline
\end{tabular}

What are the main input features?

ML models are data-depending models, without a constitution of high-quality training data, even the most performant algorithms theoretically will not give the expected results. Indeed, robust ML models can be useless when they are trained on inadequate, inaccurate, or irrelevant data. In the same context a wide variety of inputs were suggested in the reviewed articles, Figure 3 shows the classification of these parameters in six categories, viz.:

- Geography: This category of inputs indicates the agroclimatic regions, which is a land unit suitable for a certain range of crops and cultivars. Table 4 shows that 19 papers built their RS using geographic data among other variables which confirms the importance of this type of inputs, mainly because it works as an identifier that is unique to every farm.

- Weather conditions (WCs): Weather plays a major role in determining the success of agricultural pursuits. For farmers, timing is critical in the obtainment of resources, such as: fertilizer and seed, but also forecasting likely weather in the upcoming season, informing on how much irrigation is needed, as well as temperature that can affect crop growth. These factors can be determined by recording hourly, daily, or weekly, temperature, rainfall, solar radiation, wind speed, evaporation, relative humidity, and evapotranspiration. In this SLR, WCs were used in 75\% of the reviewed articles as Table 4 indicate.

- Soil propriety_(SP): All soils contain mineral particles, organic matter, water, and air. The combinations of these components determine the soil's quality, which depends both on its physical properties (texture, color, type, porosity, bulk density, etc.) and chemical properties (soil pH, soil salinity, nutrients availability, soil electrical conductivity etc.). Table 4 confirms that soil characteristics are the mandatory inputs on which researchers-built crop RSs.

Table 4: Input variables categories used for CR in literature.

\begin{tabular}{|c|c|c|c|c|c|}
\hline Geography & Weather & Soil & Crop & Production & Market \\
\hline $\begin{array}{l}\text { Location, Hill area, River } \\
\text { ground, Depth, Region, } \\
\text { Elevation, Slope }\end{array}$ & $\begin{array}{l}\text { Temperature, Rainfall, Humidity, } \\
\text { Evapotranspiration, Solar radiation, } \\
\text { Atmospheric pressure }\end{array}$ & $\begin{array}{l}\text { PH value, Nutrients availability, Soil } \\
\text { type, Soil EC, Texture, Depth, Color, } \\
\text { Bulk density }\end{array}$ & $\begin{array}{l}\text { Needed nutrients, } \\
\text { Seasonal } \\
\text { information, } \\
\text { Weather } \\
\text { information, Crop } \\
\text { damage }\end{array}$ & $\begin{array}{l}\text { Yield per unit, } \\
\text { Profitability } \\
\text { per unit }\end{array}$ & $\begin{array}{l}\text { Demand, } \\
\text { Market Price, } \\
\text { Cost, Benefit }\end{array}$ \\
\hline
\end{tabular}

Soil physical properties:

- Soil texture: Refers to the size of the particles that make up the soil and depends on the proportion of sand, silt and clay-sized particles and organic matter in the soil, it can influence whether soils are free draining, whether they hold water and how easy it is for plant roots to grow.

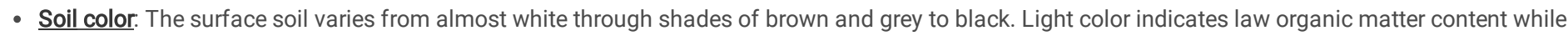
clave color indicates a high organic matter content.

- Soil type: It describes the way the sand, silt and clay particles are clumped together. Organic matter (decaying plants and animals) and soil organisms like earthworms and bacteria influence soil structure. it is important for plant growth, regulating the movement of air and water, influencing root development and affecting nutrient availability. 
- Soil porosity: It refers to the pores within the soil. Porosity influences the movement of air and water. Healthy soils have many pores between and within the aggregates. Poor quality soils have few visible pores, cracks, or holes.

- Bulk density: It is the proportion of the weight of a soil relative to its volume. Bulk density is an indicator of the amount of pore space available within individual soil horizons and it reflects the soil's ability to function for structural support, water and solute movement, and soil aeration.

Soil chemical properties:

- Soil pH: Soil reactivity is expressed in terms of pH and is a measure of the acidity or alkalinity of the soil. More precisely, it is a measure of hydrogen ion concentration in an aqueous solution and ranges in soils from 3.5 (very acid) to 9.5 (very alkaline). The effect of pH is to remove from the soil or to make available certain ions.

- Soil salinity: It is the salt content in the soil; the process of increasing the salt content is known as salinization. Salts occur naturally within soils and water. Salination can be caused by natural processes such as mineral weathering or by the gradual withdrawal of an ocean.

- Nutrients availability: Sixteen nutrients are essential for plant growth and living organisms in the soil. These fall in two different categories namely macro and micronutrients. The macronutrients include Carbon (C), Oxygen (O), Hydrogen ( $H)$, Nitrogen (N), Phosphorus (P), Potassium (K), Calcium (Ca), Magnesium (Mg), Sulphur (S) and are the most essential nutrients to plant development whereby a high quantity of these is needed. The micronutrients on the other hand are needed in smaller amounts, however they are still crucial for plant development and growth, these include Iron (Fe), Zinc (Zn), Manganese (Mn), Boron (B), Copper (Cu), Molybdenum (Mo) and Chlorine (Cl). Nearly all plant nutrients are taken up in ionic forms from the soil solution as cations or as anions.

- Soil Electrical Conductivity_(SEC): It is an indirect measurement that correlates very well with several soil physical and chemical properties. Electrical conductivity is the ability of a material to conduct (transmit) an electrical current. As measuring soil electrical conductivity is easier, less expensive, and faster than other soil properties measurements, it can be used as a good tool for obtaining useful information about soil.

- Crop propriety_(CP): Some crops are very labor-intensive. Some crops require more skill than others. Some crops are riskier than others (high profit if it's a good year but high chance of crop failure if the weather is bad), and some farmers are more able to cope with those risks. Each crop has its suitable amount needed of nutrients, optimal weather conditions and optimal soil properties. Unfortunately, there is no universal structure or data source for this kind of crop information, so researchers in different reviewed papers uses data mining techniques to extract knowledge from raw data, where FL shows high quality results, because of its rules generating model.

- CPR: There are a lot of crop types produced in farms not all of them are suitable for producing in all areas. So, considering CPR of each one of them for every farm is very important to recommend and predict the crop productivity. Almost $90 \%$ of the reviewed papers are using supervised learning, where crop yield or crop profitability, in ton/hectare or $\mathrm{kg} / \mathrm{hectare}$, were used as the dependent variable.

- Market: Even with a high yield, decision about recommending the crop cannot be taken without knowing its price for the period of sell, as well as what is its cost. The price of a specific crop is determined through demand/supply in the market; however, it can be predicted using historical data. In the other hand, cost can only be given by the farmer himself, ultimately it remains difficult to gather such data. Table 5 confirms this claim with just four papers using market information.

Table 5: Distribution of papers by feature classes.

\begin{tabular}{ccc}
\hline Feature class & Number of studies & References \\
\hline WCs & $\mathbf{2 0}$ & {$[32,33,35,36,37,40,41,42,39,50$,} \\
& & $54,57,58,64,71,43,60,67,44,45]$ \\
SP & $\mathbf{1 9}$ & {$[32,35,36,37,38,40,41,42,39$,} \\
& & $50,57,69,68,71,43,65,66,60,45]$ \\
\hline Geography & $\mathbf{1 7}$ & {$[35,33,36,37,38,40,41,42,39$,} \\
& & $50,54,69,71,65,70,67,45]$ \\
CPR & $\mathbf{9}$ & {$[32,35,40,39,50,64,70,44,45]$} \\
CP & $\mathbf{9}$ & {$[35,39,50,54,57,69,64,67,44]$} \\
\hline Market & $\mathbf{4}$ & {$[32,35,37,40]$} \\
\hline
\end{tabular}

Table 6 below presents the number of papers for each variable; it indicates that from all the features cited above temperature and rainfall are the widely used parameters. This finding is coherent with the fact that WCs have an important impact on the CPR and determine the soil's sustainability, nevertheless, it remains necessary to extract other information to build an efficient $\mathrm{CR}$. This information was grouped previously in the soil property category and they are pHvalue, soil type and nutrient availability where they were cited respectively in [15], [11] and [10]. Less important variables occurred in a range of 1 to 6 and they are a mix of all categories of features such as Elevation for geography, salinity for soil characteristics and humidity in weather conditions. The number of articles included in this SLR, could give a relevant order of variable importance evolved in a CR algorithm which is statistically supported by the limited number of research papers in precision agriculture dedicated to $\mathrm{CR}$.

Table 6: Distribution of papers by features.

Page 14/23 


\begin{tabular}{ccl}
\hline Feature & Number of studies & References \\
\hline Temperature & $\mathbf{1 7}$ & $\begin{array}{l}{[46,52,61,49,54,55,51,56,47,} \\
\end{array}$ \\
& $\mathbf{5 7}, 58,64,43,60,70,67,45]$ \\
Rainfall & $\mathbf{1 6}$ & {$[46,61,52,49,54,55,51,56,47$,} \\
\hline & & $63,64,71,60,70,67,45]$ \\
\hline pH-value & $\mathbf{1 4}$ & {$[46,48,51,56,59,47,63,57,69$,} \\
\hline & & $43,65,66,60,67]$ \\
Soil type & $\mathbf{1 0}$ & {$[46,52,48,61,54,51,47,65,67,45]$} \\
\hline Nutrients & $\mathbf{9}$ & {$[46,61,51,59,68,43,65,66,45]$} \\
\hline Humidity & $\mathbf{6}$ & {$[49,53,58,64,43,45]$} \\
\hline Yield rate & $\mathbf{5}$ & {$[61,49,55,64,70]$} \\
\hline EC soil & $\mathbf{5}$ & {$[48,53,63,69,66]$} \\
\hline Salinity & $\mathbf{5}$ & {$[53,59,69,43,65]$} \\
\hline Crop type & $\mathbf{4}$ & {$[54,34,35,50]$} \\
\hline Pressure & $\mathbf{2}$ & {$[53,58]$} \\
\hline Soil color & $\mathbf{2}$ & {$[63,60]$} \\
\hline Elevation & $\mathbf{2}$ & {$[71,45]$} \\
Soil porosity & $\mathbf{1}$ & {$[46]$} \\
\hline & & \\
\hline
\end{tabular}

Which evaluation parameters and evaluation approaches have been used?

Several evaluation metrics have been used. Table 7 below gives information about metrics used for evaluation techniques in the reviewed studies. This SLR restricted to the CS, which make classification metrics such as: Accuracy, Precision or Recall, the most popular performance metrics used in the studies of this SLR.

Table 7: Distribution of articles by performance metrics.

\begin{tabular}{crl}
\hline Metric & Number of studies References \\
\hline Accuracy & 19 & {$[46,52,48,54,56,59,47,35,36,38$,} \\
& & $42,50,71,65,60,45]$ \\
Precision & 10 & {$[52,48,36,37,39,58,68,65]$} \\
Recall & 7 & {$[48,37,39,52,58,68,65]$} \\
F-measure & 5 & {$[37,52,68,65]$} \\
Sensitivity & 2 & {$[52,36]$} \\
Specificity & 2 & {$[52,36]$} \\
MSE & 2 & {$[33,45]$} \\
\hline RMSE & 2 & {$[48,70]$} \\
MAE & 1 & {$[48]$} \\
No metric & 11 & {$[61,49,53,55,51,63,32,34,40,41$,} \\
& & $57,64,43,67]$ \\
\hline
\end{tabular}

Accuracy is the proportion of true results among the total number of cases examined, which has the highest number of occurrences in our SLR, more than precision, which refers to the fraction of relevant recommendation among the retrieved crops, and recall, which refers to the fraction of retrieved recommendation among all relevant crops.

Another important result is the existing of studies evaluating their results by using regression error metrics such us: RMSE, MSE and the mean absolute error (MAE) metrics. The reason is that a study may use CPR as an output of the model developed, then, it chooses the crop which has the highest rate.

What is striking in the Table 7 is the remarkable number of papers that are not evaluated by any performance criteria. The most likely cause of this result is the difficulty to verify whether the recommended crop is truly the correct one. For this reason, most of studies seek the help of experts or farmers to judge the relevance of the suggested crops [50].

What are the current challenges in CR?

This section puts into terms challenges encountered in the extant research, these challenges are observed through three layers: the proposed algorithm, the used data and the evaluation preferences. Most studies have almost exclusively focused on the exploitation of CF algorithms for classification and clustering, more precisely: DTs, SVM, ANNs and NBC. Several gaps and shortcomings were identified in these techniques, namely the cold start problem, where the system cannot draw any inferences for users or items about which has not yet gathered sufficient information. A closer look to the literature, reveals that these proposed adaptations are very classical, since the field of RS has known a significant improvement due to entertainment companies, new algorithms were developed. For Instance, the Netflix Prize was an open competition for the best CF algorithm to predict user ratings for movies [72]. On September 21, 2009, the grand prize was given to the BellKor's Pragmatic Chaos team, which bested Netflix's own algorithm for predicting ratings by $10.06 \%$ [73]. During this competition MF became widely known due to its effectiveness, and important steps were taken in later years towards some very successful algorithms, which 
share the same basis of latent factor and user/item representations. Unfortunately, there was no article -so far- that suggested an implementation of these modern techniques for CR. A potential barrier that may face researchers in their quest to solve this delay is the available data, Figure 5 shows that more than $50 \%$ of the reviewed papers were published by Asian researchers, and more precisely Indian researchers, together with researchers all over the world using Indian datasets, where SP parameters, CPR parameters and parameters for a very long period of time and by different states/districts, are available in government official websites. Notwithstanding, these data are inaccessible for foreign scientists. Furthermore, the proposed structure of data presents another challenge, where the vast majority of the well performed RS are fitted by a user/item rating matrix, and the user's demographic data for hybrid systems, where ratings are either explicit or implicit (number of clicks, number of page visits, the number of times a song was played, etc.) So different complex preprocessing techniques are required. Even though, the sparsity remains a potential challenge to deal with. Finally, the high correlation degree that was observed for performance metrics and evaluations of the model, based on anonymous experts raises a very important question about the reliability of these results, hence the proposed algorithm.

[1] First introduced as a method to create a control system by synthesizing a set of linguistic control rules obtained from experienced human operators. In a Mamdani system, the output of each rule is a fuzzy set.

\section{Discussion}

During the last decade, the use of technology to enhance the agricultural processes has been very remarkable. For CR, we can see clearly from Table 3 that there has been some success in this direction. Exploration of the used techniques shows us that most of the times, the problem is formulated as a classification problem, where algorithms as DTs and NBC, etc. give remarkable results. Fuzzy systems have been used in other cases, to model the uncertainty in input variables that were categorized and analyzed to facilitate the choice for future researchers. This study reveals also some challenges that are being faced when creating a CS method, like the unavailability of the data, more specifically benchmarking datasets to compare the models, the input variables are quite different from a study to another, and the difficulty in measuring the performance of the proposed methods; some papers compare their model predictions to what the farmer has actually cultivated, while others compare to domain experts' recommendations. Historical evidence shows that great scientific achievements were guided by industrial needs, unfortunately, precision agriculture and CR haven't yet gained the attention that it deserves from different stakeholders, basically in emergent countries where agriculture is the most valuable resource. Major improvements in agricultural domain will certainly appear by integrating the successful algorithms of RS that were developed for entertainment companies, whom humankind might benefit differently. Finally, in this paper we've studied 40 well selected articles from different reliable sources. Nevertheless, this number remains statistically insignificant and more similar works are needed to illuminate the path for new researchers that are willing to innovate and effectively contribute to the field

\section{Conclusion And Future Work}

In this SLR we have presented a detailed analysis of 40 articles published from 2010 to 2020 about the CR problem as well as the main achievements, and current challenges. Although agriculture is the most valuable resource in emerging nations, precision agriculture and CR haven't yet attracted enough interest from various stakeholders. By implementing the CR's effective algorithms, which were originally created for entertainment enterprises, which humans may benefit in multiple ways, significant advancements in the agricultural area will undoubtedly occur.

The SLR was conducted with the aim of providing insights of the kind of solutions that were proposed in the recent years for the CS task. Such insights are valuable in suggesting new directions for research studies and in providing a good understanding of the recent research trends.

As a perspective, we look forward to propose new methods that are inspired from the current development of RS in other domains and tackling the specific challenges present for the agricultural context.

\section{Declarations}

Ethics approval and consent to participate

Not applicable

Consent for publication

We confirm our consent for the publication of the present paper.

Availability of data and materials

Not applicable.

Competing interests

No, we declare that the authors have no competing interests as defined by Springer, or other interests that might be perceived to influence the results and/or discussion reported in this paper.

Funding 
This research was funded by the business unit called AgriEdge by Mohammed VI Polytechnic University (UM6P), in the framework of the Digital Farming Project, between Mohammed VI Polytechnic University (UM6P), Benguerir, Kingdom of Morocco and Massachusetts Institute of Technology (MIT), Boston, USA.

Author's contribution

The authors equally contributed.

Acknowledgement

We acknowledge Agriedge (a company specialized in precision agriculture) for their financial support, as well as the Mohammed VI Polytechnic university (UM6P) for the material and administrative support. We also thank the reviewers for their valuable tips that led to an improved version of this article.

\section{References}

[1] I. Portugal, P. Alencar, D. Cowan, The use of machine learning algorithms in recommender systems: A systematic review, Expert Systems with Applications 97 (2018) 205-227. doi:10.1016/j.eswa.2017.12.020.

[2] K. A. Klompenburg T., C. C., Crop yield prediction using machine learning: A systematic literature review, Computers and Electronics in Agriculture 177 (January) (2020) 105709. doi:10.1016/j.compag.2020.105709.

[3] A. Chlingaryan, S. Sukkarieh, B. Whelan, Machine learning approaches for crop yield prediction and nitrogen status estimation in precision agriculture: A review, Computers and Electronics in Agriculture 151 (2018) 61-69. doi:10.1016/j.compag.2018.05.012.

[4] R. Burke, Hybrid recommender systems: Survey and experiments, User Modeling and User-Adapted Interaction 12 (2002) $331-370$. doi:10.1023/A:1021240730564.

[5] A. Poriya, T. Bhagat, N. Patel, R. Sharma, Non-personalized recommender systems and user-based collaborative recommender systems, International Journal of Applied Information Systems 6 (9) (2014) 22-27. doi:10.1.1.428.6731.

[6] R. Burke, Knowledge-based recommender systems, https://www.cs.odu. edu/ mukka/cs795sum09dm/Lecturenotes/Day6/burke-elis00.pdf (2000).

[7] E. Aïmeur, G. Brassard, J. M. Fernandez, F. S. M. Onana, Privacy- preserving demographic filtering, in: Proceedings of the 2006 ACM Symposium on Applied Computing, Association for Computing Machinery, New York, NY, USA, 2006, p. 872-878. doi:10.1145/1141277.1141479.

[8] J. S. Breese, D. Heckerman, C. Kadie, Empirical analysis of predictive algorithms for collaborative filtering, in: Proceedings of the Fourteenth Conference on Uncertainty in Artificial Intelligence, UAl'98, Morgan Kaufmann Publishers Inc., 1998, p. 43-52. doi:10.5555/2074094.2074100.

[9] J. Bobadilla, F. Ortega, A. Hernando, J. Alcal'a, Knowledge-Based Systems Improving collaborative filtering recommender system results and performance using genetic algorithms, Knowledge-Based Systems 24 (8) (2011) 1310-1316. doi:10.1016/j.knosys.2011.06.005.

[10] N. Tsapatsoulis, O. Georgiou, Investigating the scalability of algorithms, the role of similarity metric and the list of suggested items construction scheme in recommender systems, International Journal on Artificial Intelligence Tools 21 (4) (2012) 1-29. doi:10.1142/S0218213012400180.

[11] H.-T. Cheng, L. Koc, J. Harmsen, T. Shaked, T. Chandra, H. Aradhye, G. Anderson, G. Corrado, W. Chai, M. Ispir, R. Anil, Z. Haque, L. Hong, V. Jain, X. Liu, H. Shah, Wide amp; deep learning for recommender systems, in: Proceedings of the 1st Workshop on Deep Learning for Recommender Systems, DLRS 2016, Association for Computing Machinery, New York, NY, USA, 2016, p. 7-10. doi:10.1145/2988450.2988454.

[12] H.-J. Xue, X. Dai, J. Zhang, S. Huang, J. Chen, Deep matrix factorization models for recommender systems, in: Proceedings of the Twenty-Sixth International Joint Conference on Artificial Intelligence, IJCAI-17, International Joint Conference on Artificial Intelligence, 2017, pp. 3203-3209. doi:10.24963/ijcai.2017/447.

[13] X. Wang, X. He, M. Wang, F. Feng, T.-S. Chua, Neural graph collaborative filtering, in: Proceedings of the $42^{\text {nd }}$ International ACM SIGIR Conference on Research and Development in Information Retrieval, SIGIR'19, Association for Computing Machinery, 2019, p. 165-174. doi:10.1145/3331184.3331267.

[14] K. R, P. Kumar, B. Bhasker, DNNRec: A novel deep learning-based hybrid recommender system, Expert Systems with Applications 144 (2020). doi:10.1016/j.eswa.2019.113054.

[15] A. v. d. Oord, S. Dieleman, B. Schrauwen, Deep content-based mu- sic recommendation, in: Proceedings of the 26th International Conference on Neural Information Processing Systems - Volume 2, NIPS'13, Curran Associates Inc., Red Hook, NY, USA, 2013, p. 2643-2651. doi:10.5555/2999792.2999907.

[16] D. Kim, C. Park, J. Oh, S. Lee, H. Yu, Convolutional matrix factorization for document context-aware recommendation, in: Proceedings of the 10th ACM Conference on Recommender Systems, RecSys '16, Association for Computing Machinery, New York, NY, USA, 2016, p. $233-240$.

doi:10.1145/2959100.2959165.

[17] G. Srivastav, S. Kant, Review on e-Learning Environment Development and context aware recommendation systems using Deep Learning, International Conference on Recent Developments in Control, Automation and Power Engineering, RDCAPE (2019). doi:10.1109/RDCAPE47089.2019.8979066. 
[18] S. Sedhain, A. K. Menon, S. Sanner, L. Xie, Autorec: Autoencoders meet collaborative filtering, in: Proceedings of the 24th International Conference on World Wide Web, WWW '15 Companion, Association for Computing Machinery, New York, NY, USA, 2015, p. 111-112. doi:10.1145/2740908.2742726.

[19] D. Liang, R. G. Krishnan, M. D. Hoffman, T. Jebara, Variational au- toencoders for collaborative filtering, in: Proceedings of the 2018 World Wide Web Conference, WWW '18, International World Wide Web Conferences Steering Committee, Republic and Canton of Geneva, CHE, 2018, p. 689-698. doi:10.1145/3178876.3186150.

[20] L. Li, D. Wang, T. Li, D. Knox, B. Padmanabhan, Scene: A scalable two- stage personalized news recommendation system, in: Proceedings of the 34th International ACM SIGIR Conference on Research and Development in Information Retrieval, Association for Computing Machinery, New York, NY, USA, 2011, p. 125-134. doi:10.1145/2009916.2009937.

[21] S. Purushotham, Y. Liu, C.-C. J. Kuo, Collaborative topic regression with social matrix factorization for recommendation systems, in: Proceedings of the 29th International Conference on International Conference on Machine Learning, Omnipress, Madison, WI, USA, 2012, p. 691-698. doi: $10.5555 / 3042573.3042664$.

[22] L. Li, W. Chu, J. Langford, R. E. Schapire, A contextual-bandit approach to personalized news article recommendation, Proceedings of the 19th International Conference on World Wide Web (2010). doi:10.1145/1772690.1772758.

[23] L. Song, C. Tekin, M. van der Schaar, Online learning in large-scale contextual recommender systems, IEEE Transactions on Services Computing 9 (3) (2016) 433-445. doi:10.1109/TSC.2014.2365795.

[24] G. Zheng, F. Zhang, Z. Zheng, Y. Xiang, N. J. Yuan, X. Xie, Z. Li, Drn: A deep reinforcement learning framework for news recommendation, in: Proceedings of the World Wide Web Conference, International World Wide Web Conferences Steering Committee, Republic and Canton of Geneva, CHE, 2018, p. 167-176. doi:10.1145/3178876.3185994.

[25] L. M. De Campos, J. M. Fern'andez-Luna, J. F. Huete, M. A. Rueda- Morales, combining content-based and collaborative recommendations: A hybrid approach based on Bayesian networks, International Journal of Ap- proximate Reasoning 51 (7) (2010) 785-799. doi:10.1016/j.ijar.2010.04.001.

[26] V. Kant, K. K. Bharadwaj, Enhancing Recommendation quality of content-based filtering through collaborative predictions and fuzzy similarity measures, Procedia Engineering 38 (2012) 939-944. doi:10.1016/j.proeng.2012.06.118.

[27] J. Lacasta, F. J. Lopez-Pellicer, B. Espejo-Garc'ıa, J. Nogueras-Iso, F. J. Zarazaga-Soria, Agricultural recommendation system for crop protec- tion, Computers and Electronics in Agriculture 152 (June) (2018) 82-89. doi:10.1016/j.compag.2018.06.049.

[28] M. A. Salam, M. A. Mahmood, Y. M. Awad, M. Hazman, N. El Bendary, A. E. Hassanien, M. F. Tolba, S. M. Saleh, Climate Recommender System for Wheat Cultivation in North Egyptian Sinai Peninsula, in: Advances in Intelligent Systems and Computing, Vol. 303, Springer Verlag, 2014, pp. 121-130. doi:10.1007/978-3-319-08156-413.

[29] A. lorshase, O. I. Charles, A Well-Built Hybrid Recommender System for Agricultural Products in Benue State of Nigeria, Journal of Software Engineering and Applications 08 (11) (2015) 581-589. doi:10.4236/jsea.2015.811055.

[30] S. Jaiswal, T. Kharade, N. Kotambe, S. Shinde, Collaborative Recommendation System for Agriculture Sector, ITM Web of Conferences 32 (2020) 03034. doi:10.1051/itmconf/20203203034.

[31] M. J. Page, J. E. McKenzie, P. M. Bossuyt, I. Boutron, T. C. Hoffmann, C. D. Mulrow, L. Shamseer, J. M. Tetzlaff, D. Moher, Updating guidance for reporting systematic reviews: development of the prisma 2020 statement, Journal of Clinical Epidemiology 134 (2021) $103-112$. doi:10.1016/j.jclinepi.2021.02.003.

[32] B. M. Elomda, H. A. Hefny, F. Ashmawy, A Multi-Level Linguistic Fuzzy Decision Network, in: Advances in Intelligent Systems and Computing, Springer, Cham, 2015. doi:10.1007/978-3-319-11310-4.

[33] F. Farnood Ahmadi, N. Farsad Layegh, Integration of artificial neural network and geographical information system for intelligent assessment of land suitability for the cultivation of a selected crop (2015). doi:10.1007/s00521-014-1801-z.

[34] R. Kumar, M. P. Singh, P. Kumar, J. P. Singh, Crop Selection Method to maximize crop yield rate using machine learning technique (2015). doi:10.1109/ICSTM.2015.7225403.

[35] A. Kawtrakul, R. Amorntarant, H. Chanlekha, Development of an expert system for personalized crop planning, in: 7th International ACM Conference on Management of Computational and CollEctive Intelligence in Digital EcoSystems, MEDES 2015, Association for Computing Machinery, 2015 , pp. $250-257$. doi:10.1145/2857218.2857272.

[36] N. Deepa, K. Ganesan, Multi-class classification using hybrid soft decision model for agriculture crop selection, Neural Computing and Applications 30 (4) (2016) 1025-1038. doi:10.1007/s00521-016-2749-y.

[37] A. U, A. S, B. L. N, R. Sridhar, Fuzzy Logic Based Hybrid Recommender of Maximum Yield Crop Using Soil, Weather and Cost, ICTACT Journal on Soft Computing 6 (4) (2016) 1261-1269. doi:10.21917/ijsc.2016.0173. 
J. Nisha, Crop recommendation system for precision agriculture, International Conference on Advanced Computing (2017). doi:10.1109/ICoAC.2017.7951740.

[39] M. J. Mokarrama, M. S. Arefin, RSF: A recommendation system for farmers, 2018, pp. 843-850. doi:10.1109/R10-HTC.2017.8289086.

[40] R. E. V. Raja, S. Kanaga SubaRishi, Demand based crop recommender system for farmers, in: Proceedings -2017 IEEE Technological Innovations in ICT for Agriculture and Rural Development, pp. 194-199. doi:10.1109/TIAR.2017.8273714.

[41] A. Kapoor, A. K. Verma, Crop Selection Using Fuzzy Logic-Based Expert System, Applications of Soft Computing for the Web (2017). doi:10.1007/978981- 10-7098-3 8.

[42] N. Deepa, K. Ganesan, Decision-making tool for crop selection for agriculture development, Neural Computing and Applications 31 (4) (2017) 12151225. doi:10.1007/s00521-017-3154-x.

[43] R. Joshi, H. Fadewar, P. Bhalchandra, Fuzzy based intelligent system to predict most suitable crop, in: Proceedings of the International Conference on Communication and Signal Processing, Atlantis Press, 2017, pp. 379-383. doi:10.2991/iccasp-16.2017.58.

[44] C. Filippi, R. Mansini, E. Stevanato, Mixed integer linear programming models for optimal crop selection, Computers and Operations Research 81 (2017) 26-39. doi:10.1016/j.cor.2016.12.004.

[45] T. Islam, T. A. Chisty, A. Chakrabarty, A deep neural network approach for crop selection and yield prediction in Bangladesh, IEEE Region 10 Humanitarian Technology Conference (2019). doi:10.1109/R10-HTC.2018.8629828.

[46] N. H. Kulkarni, G. N. Srinivasan, B. M. Sagar, N. K. Cauvery, Improving Crop Productivity Through A Crop Recommendation System Using Ensembling Technique, Proceedings 3rd International Conference on Computational Systems and Information Technology for Sustainable Solutions (2018). doi:10.1109/CSITSS.2018.8768790.

[47] Z. Doshi, S. Nadkarni, R. Agrawal, N. Shah, Agro-consultant: Intelligent crop recommendation system using machine learning algorithms, in: Fourth International Conference on Computing Communication Control and Automation (ICCUBEA), IEEE, 2018, pp. 1-6. doi:10.1109/ICCUBEA.2018.8697349.

[48] A. Arooj, M. Riaz, M. N. Akram, Evaluation of predictive data mining algorithms in soil data classification for optimized crop recommendation, International Conference on Advancements in Computational Sciences (2018). doi:10.1109/ICACS.2018.8333275.

[49] M. Kuanr, B. Kesari Rath, S. Nandan Mohanty, Crop Recommender System for the Farmers using Mamdani Fuzzy Inference Model, International Journal of Engineering \& Technology 7 (4.15) (2018). doi:10.14419/ijet.v7i4.15.23006.

[50] M. B. Anley, T. B. Tesema, A Collaborative Approach to Build a KBS for Crop Selection: Combining Experts Knowledge and Machine Learning Knowledge Discovery, in: Communications in Computer and Information Science, Vol. 1026, Springer Verlag, 2019, pp. 80-92. doi:10.1007/978-3-030-26630-1 8.

[51] S. Poongodi, M. Rajesh Babu, Analysis of crop suitability using clustering technique in Coimbatore region of Tamil Nadu, Concurrency Computation 31 (14) (2019) 1-13. doi:10.1002/cpe.5294.

[52] N. Deepa, K. Ganesan, Hybrid rough fuzzy soft classifier based multi-class classification model for agriculture crop selection, Soft Computing 23 (21) (2019) 10793-10809. doi:10.1007/s00500-018-3633-8.

[53] F.-H. Tseng, H.-H. Cho, H.-T. Wu, Applying Big Data for Intelligent Agriculture-Based Crop Selection Analysis, IEEE Access 7 (2019) $116965-116974$. doi:10.1109/access.2019.2935564.

[54] T. K. Fegade, B. V. Pawar, Network and Support Vector Machine (2020). doi:10.1007/978-981-13-9364-8 23.

[55] Meeradevi, H. Salpekar, Design and Implementation of Mobile Applica- tion for Crop Yield Prediction using Machine Learning, in 2019 Global Conference for Advancement in Technology (GCAT), IEEE, pp. 1-6. doi:10.1109/GCAT47503.2019.8978315.

[56] T. Rizaldi, H. A. Putranto, H. Y. Riskiawan, D. P. S. Setyohadi, J. Riaviandy, Decision Support System for Land Selection to Increase Crops Productivity in Jember Regency Use Learning Vector Quantization (LVQ), Proceedings - 2019 International Conference on Computer Science, Information Technology, and Electrical Engineering 1 82-85. doi:10.1109/ICOMITEE.2019.8921033.

[57] C. O. Martinez-Ojeda, T. M. Amado, J. C. Dela Cruz, In Field Proximal Soil Sensing for Real Time Crop Recommendation Using Fuzzy Logic Model, in: International Symposium on Multimedia and Communication Technology (IS-MAC), IEEE, 2019. doi:10.1109/ISMAC.2019.8836160.

[58] S. B. Kamatchi, R. Parvathi, Improvement of Crop Production Using Recommender System by Weather Forecasts, Procedia Computer Science 165 (2019) 724-732. doi:10.1016/j.procs.2020.01.023.

[59] S. A. Z. Rahman, K. C. Mitra, S. M. Islam. Soil Classification Using Machine Learning Methods and Crop Suggestion Based on Soil Series, 21st International Conference of Computer and Information Technology (2019). doi:10.1109/ICCITECHN.2018.8631943. 
[60] A. Kumar, S. Sarkar, C. Pradhan, Recommendation system for crop identification and pest control technique in agriculture, in: Proceedings of the 2019 IEEE International Conference on Communication and Signal Processing, pp. 185-189. doi:10.1109/ICCSP.2019.8698099.

[61] V. K. A. Chougule, D. Mukhopadhyay, Crop suitability and fertilizers recommendation using data mining techniques, in: Advances in Intelligent Systems and Computing, Vol. 714, Springer Verlag, 2019, pp. 205-213. doi:10.1007/978- 981-13-0224-4 19.

[62] B. Viviliya, V. Vaidhehi, The Design of Hybrid Crop Recommendation System using Machine Learning Algorithms, International Journal of Innovative Technology and Exploring Engineering 9 (2) (2019) 4305-4311. doi:10.35940/ijitee.b7219.129219.

[63] R. Aarthi, D. Sivakumar, Modeling the Hierarchical Fuzzy System for Suitable Crop Recommendation, in: Lecture Notes in Electrical Engineering, Vol. 686, Springer Science and Business Media Deutschland GmbH, 2020, pp. 199-209. doi:10.1007/978-981-15-7031-5 19.

[64] R. M.-E. M. Cadenas, M. Carmen, Development of an application to make knowledge available to the farmer: Detection of the most suitable crops for a more sustainable agriculture, Journal of Ambient Intelligence and Smart Environments 12 (5) (2020) 419-432. doi:10.3233/AIS-200575.

[65] A. M. Rajeswari, A. S. Anushiya, K. S. A. Fathima, S. S. Priya, N. Mathumithaa. Fuzzy Decision Support System for Recommendation of Crop Cultivation based on Soil Type, Proceedings of the 4th International Conference on Trends in Electronics and Informatics (2020). doi:10.1109/ICOEI48184.2020.9142899.

[66] K. Patel, H. B. Patel, A state-of-the-art survey on recommendation system and prospective extensions, Computers and Electronics in Agriculture 178 (2020). doi:10.1016/j.compag.2020.105779.

[67] S. Jain, D. Ramesh, Machine Learning convergence for weather-based crop selection, IEEE International Students' Conference on Electrical, Electronics and Computer Science (2020). doi:10.1109/SCEECS48394.2020.75.

[68] A. Liu, T. Lu, B. Wang, C. Chen, Crop Recommendation via Clustering Center Optimized Algorithm for Imbalanced Soil Data, in: 5th International Conference on Control, Robotics and Cybernetics (CRC), IEEE, 2020, pp. 31-35. doi:10.1109/CRC51253.2020.9253457.

[69] F. Sari, F. Koyuncu, Multi Criteria Decision Analysis to Determine the Suitability of Agricultural Crops for Land Consolidation Areas, International Journal of Engineering and Geosciences 6 (2) (2021) 64-73. doi:10.26833/ijeg.683754.

[70] A. Karwande, M. Wyawahare, T. Kolhe, S. Kamble, R. Magar, L. Maheshwari, Prediction of the Most Productive Crop in a Geographical Area Using Machine Learning, Lecture Notes in Networks and Systems 141 (2021) 433-441. doi:10.1007/978-981-15-7106-0 43.

[71] G. Banerjee, U. Sarkar, I. Ghosh, A Fuzzy Logic-Based Crop Recommendation System, Springer Singapore, 2021. doi:10.1007/978-981-15-7834-2 6.

[72] J. Bennett, S. Lanning, The netflix prize, http://www.cs.uic.edu/ liub/ KDD-cup-2007/NetflixPrize-description.pdf (Aug. 2007).

[73] Y. Koren, The bellkor solution to the netflix grand prize, https://netflixprize.com/assets/GrandPrize2009_BPC_BellKor.pdf (2009).

\section{Acronyms}

ANN Artificial Neural Networks.

CBF Content-Based Filtering.

CF Collaborative Filtering.

cos Cosine Similarity.

CP Crop Propriety.

CPR Crop Production Rate.

CR Crop Recommendation.

CS Crop Selection.

DNN Deep Neural Networks.

DT Decision Tree.

EC Exclusion criteria.

FL Fuzzy Logic.

HF Hybrid Filtering.

IOT Internet Of Things. 
KB Knowledge-based.

KMC K-means clustering.

KNN K-Nearest Neighbors.

LR Linear Regression.

LRM Literature Review Matrix.

LVQ Learning Vector Quantization.

MAE Mean Absolute Error.

MB Memory-Based.

MF Matrix Factorization.

ML Machine Learning

MSE Mean Squared Error.

NBC Naive Bayes Classifier.

PCS Pearson Correlation Similarity

RF Random Forest.

RMSE Root Mean Squared Error.

RQ Research Question.

RS Recommender System.

SLR Systematic Literature Review.

SP Soil propriety.

SVM Support Vector Machine.

WCs Weather Conditions.

\section{Figures}

\section{Figure 1}

Classification of recommendation systems techniques.

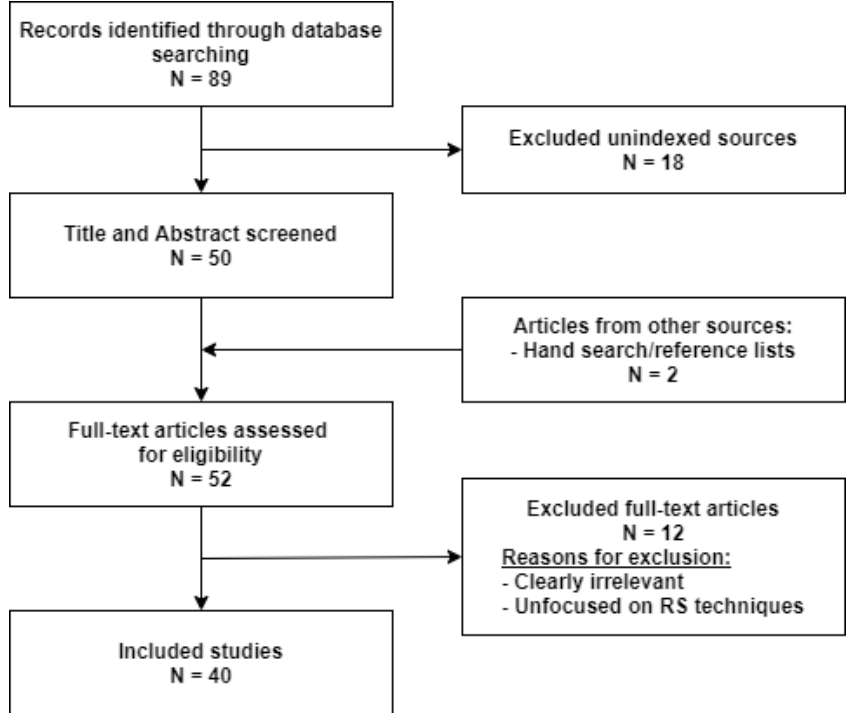


Figure 2

Flow chart of identification process of relevant CR articles.

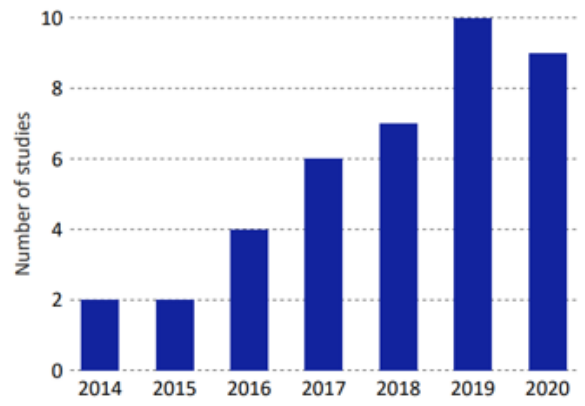

a) Distribution of selected papers since 2014

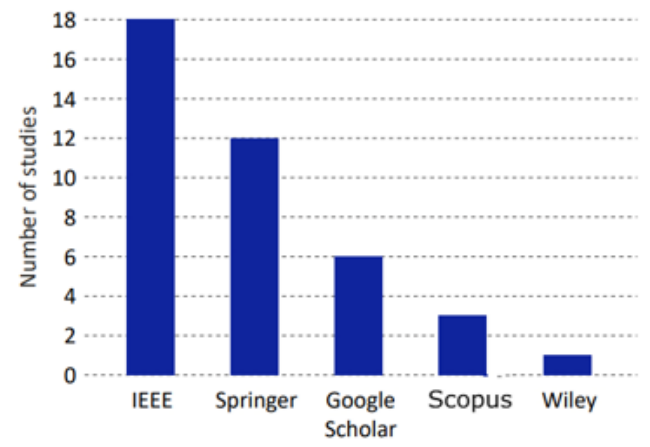

b) Distribution of papers based on selected database

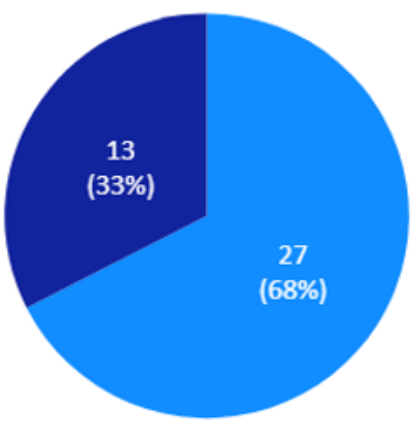

- Conference • Journal

c) Distribution by type of publication.

Figure 3

Distribution of selected papers.

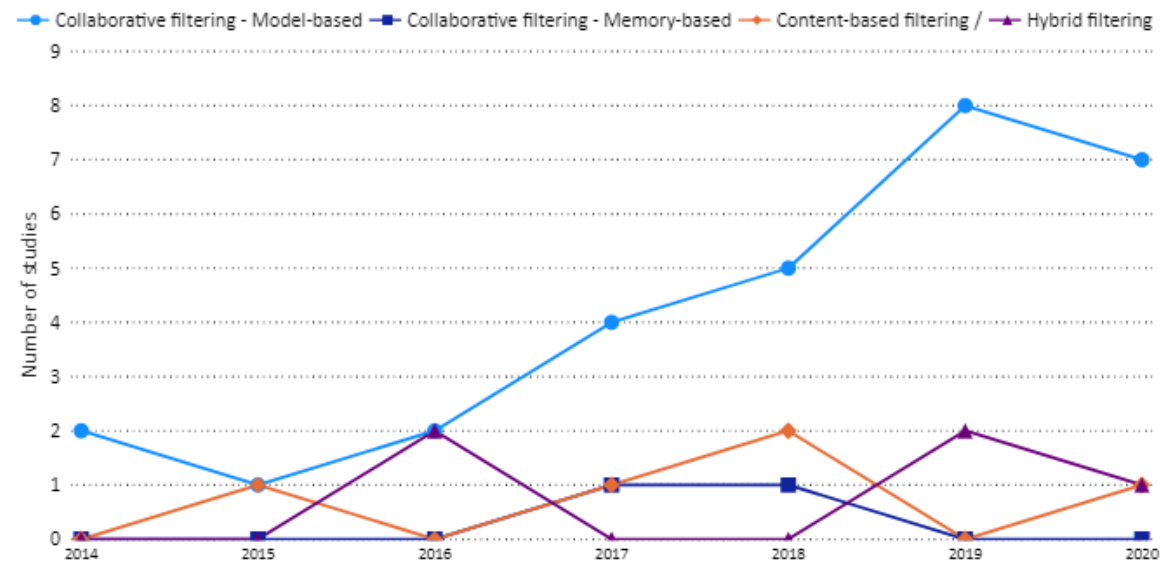

\section{Figure 4}

Timeline of articles by recommendation approaches. 


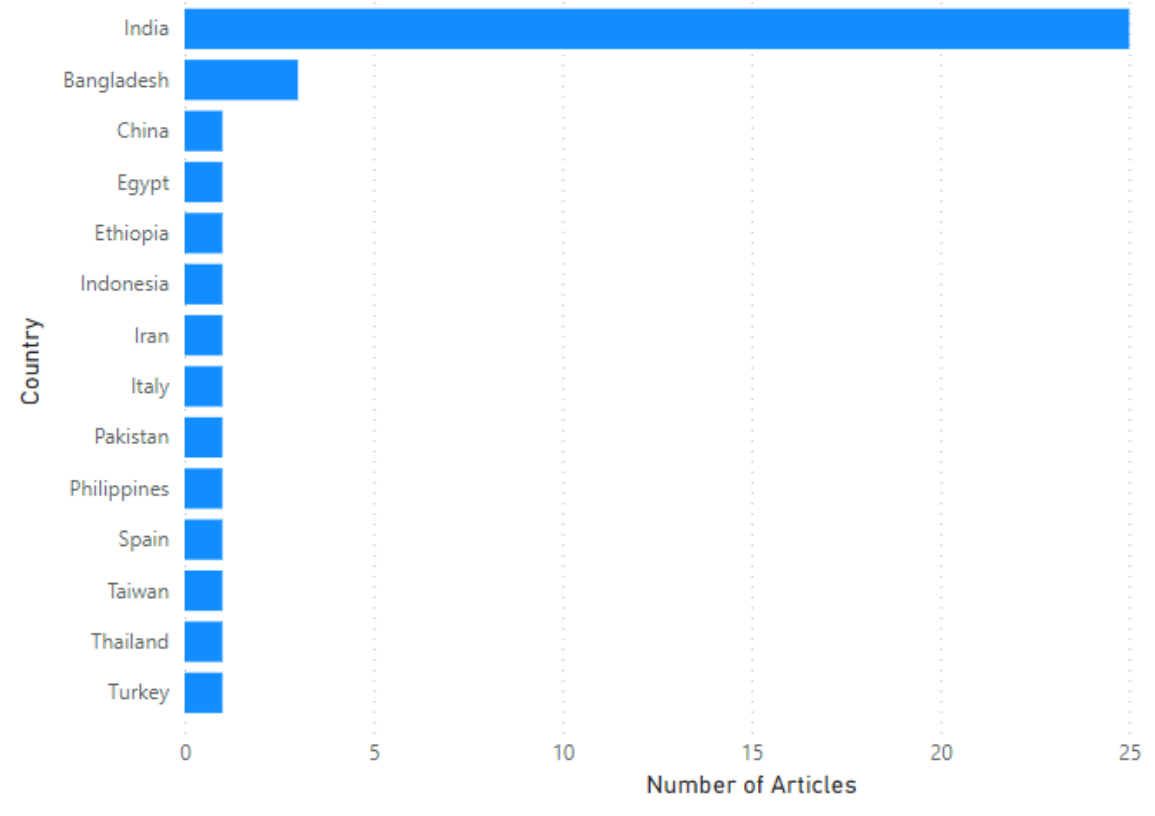

\section{Figure 5}

Articles distribution by origin countries of the dataset used. 